\title{
Communication
}

\section{Recovery of Filtered Particles by Elastic Flat-Sheet Membrane with Cross Flow}

\author{
Manoka Miyoshi, Shintaro Morisada, Keisuke Ohto and Hidetaka Kawakita *(D)
}

\section{check for}

updates

Citation: Miyoshi, M.; Morisada, S.; Ohto, K.; Kawakita, H. Recovery of Filtered Particles by Elastic Flat-Sheet Membrane with Cross Flow.

Membranes 2021, 11, 71. https:// doi.org/10.3390/membranes11020071

Academic Editor: Sanghyun Jeong

Received: 15 December 2020

Accepted: 18 January 2021

Published: 20 January 2021

Publisher's Note: MDPI stays neutral with regard to jurisdictional claims in published maps and institutional affiliations.

Copyright: (C) 2021 by the authors. Licensee MDPI, Basel, Switzerland. This article is an open access article distributed under the terms and conditions of the Creative Commons Attribution (CC BY) license (https:/ / creativecommons.org/licenses/by/ $4.0 /)$.

\author{
Department of Applied Chemistry, Saga University, Saga 840-8502, Japan; goodfish1207@gmail.com (M.M.); \\ morisada@cc.saga-u.ac.jp (S.M.); ohtok@cc.saga-u.ac.jp (K.O.) \\ * Correspondence: kawakita@cc.saga-u.ac.jp
}

\begin{abstract}
After filtration, filtered residue is recovered by a spoon, during which, the structure of the residue is destroyed, and the activity of the microorganism would be reduced. Thus, a more efficient recovery method of filtered residue is required. This study addressed the recovery method of filtered residue by the restoration of an elastic membrane, followed by cross flow. An elastic membrane composed of a copolymer of poly(ethylene glycol) diacrylate and polyacrylonitrile was prepared by photopolymerization. The pore diameter of the obtained membrane was about $10 \mu \mathrm{m}$. Silica particle (1 and $10 \mu \mathrm{m})$ and Nannochloropsis sp. $(2 \mu \mathrm{m})$ suspension was filtered, demonstrating that silica particles of $10 \mu \mathrm{m}$ were filtered perfectly, whereas the filtration percentage of $1 \mu \mathrm{m}$ silica particles and Nannochloropsis sp. was lower. After the filtration, the applied pressure was released to restore the elastic membrane which moved the filtered particles up, then the filtered residue was recovered by cross flow above the membrane, demonstrating that $71 \%$ of the filtered $10 \mu \mathrm{m}$ silica particles was recovered. The elastic behavior of the membrane, along with the cross flow, has the potential to be used as a technique for the recovery of the filtered residues. This proposed scheme would be used for the particle recovery of ceramics, cells, and microorganisms from a lab scale to a large-scale plant.
\end{abstract}

Keywords: elastic membrane; filtration; recovery; cross flow; filtration residue

\section{Introduction}

During the filtration of cells and microorganisms with the filter, a cake layer of residue is formed on the pore [1,2]. To recover the filter residue on the membrane, it requires sweeping with a spoon. However, the structure and the activity of the filtered residues might be lost, and thus a novel technique for the recovery of the filtered residues is needed.

For the filtration and separation of particles dispersed in solution, so far, we have proposed the recovery method of particles being filtered by a spherical gel layer packed in a column. Colloidal suspension, as a separation target, was loaded on the spherical gel layer, and water was flowed through the column for the separation [3-5]. The larger colloidal particles were filtered at the top of the gel layer, and the smaller particles were transported to the inner domain of the column. To recover the large filtered colloidal particles, the applied pressure was released to restore the gel layer. The filtered residue was raised up by the elasticity of the gel layer. The raised particles were recovered by cross flow across the column [6]. However, the filtered particles in the inner part of the gel layer remained there.

Synthetic membrane and gel are composed of synthetic polymers. Photopolymerization is one of the methods used for polymerization. Photopolymerization can be applied to the local domain and to the surface. Ethylene glycol diacrylate is commonly used for many applications because ethylene glycol is hydrophilic, which prevents the hydrophobic interaction $[7,8]$. For instance, the membrane was modified with ethylene glycol for the separation of water and oil [9]. The membrane composed of polyethylene glycol was prepared in a microchannel to determine the deformation of the membrane by applied pressure of fluid flow [10]. The linear domain composed of polyethylene glycol has the characteristics of extension and shrinkage, applicable for the deformation of membrane. 
Direct observation of membrane and gel deformation in membrane modules is still difficult. Therefore, a mathematical model based on direct mechanical data of the membrane has been analyzed instead of the observation [11]. However, the effect of fluid flow in each pore was still not analyzed. So far, though the polymeric gel membrane in the microchannel was deformed by fluid flow in order to be observed directly $[12,13]$, membrane deformation along with the particle filtration has not yet been analyzed and has not applied for actual separation.

In this study, elastic membrane as a flat sheet was prepared by photopolymerization. Colloidal suspensions were filtered by the elastic membrane, and the filtered residue was recovered by the restoration of the elastic membrane and cross flow, as shown in Figure 1. Concretely, (a) when colloidal suspension is filtered by the elastic membrane, the membrane was deformed by the applied pressure; (b) after releasing the applied pressure, the elastic membrane was restored to raise the filtered residues up; (c) raised residue was recovered by the cross flow above the membrane surface. In the case of cross flow, shear stress by fluid on the microfiltration and ultrafiltration membrane pore sweeps the filtered particles. Back flow is generated from the opposite direction to the filtered flow direction to wash out the residues. If the residue still remains on the membrane pore, a more effective method for the recovery is required. The originality of this study is that the membrane deformation with the elasticity and back flow, along with the cross flow, enhances the recovery efficiency of the filtered particles. Specifically, poly(ethylene glycol) diacrylate (Mn 575) and acrylonitrile was used as a monomer for the polymerization. Poly(ethylene glycol diacrylate) (PEGDA) has elasticity, because the oligomer has the intrinsic "springlike" structure [14]. Added polyacrylamide can form the porous structure because of its high exclusion volume in the polymer matrix. Colloidal particles of silica particles (1 and $10 \mu \mathrm{m})$ and Nannochloropsis sp. $(2 \mu \mathrm{m})$ were used. The rigid and soft particles of silica particles and Nannochloropsis sp., respectively, were filtered, and the recovery of the filtered residue by the elasticity and cross flow was examined.

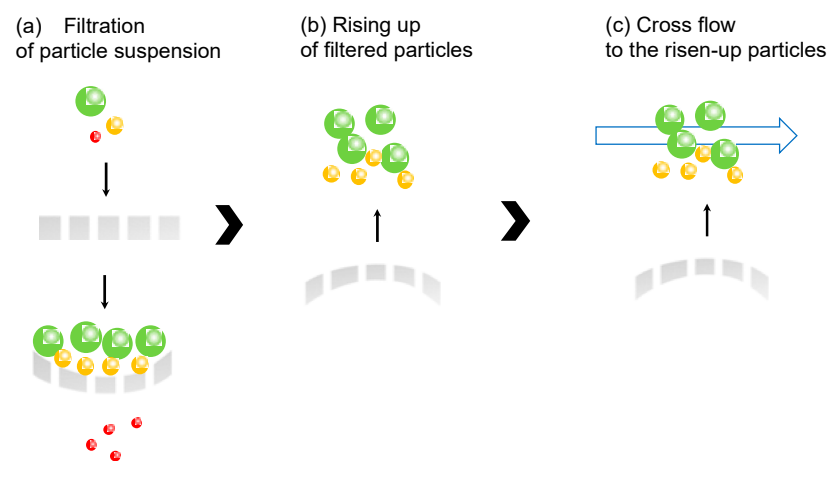

Figure 1. Illustrated image of the recovery of filtered particles by elasticity of the membrane and cross flow.

\section{Materials and Methods}

\subsection{Materials}

Monomer of poly(ethylene glycol) diacrylate (PEGDA) $(\mathrm{Mn}=575)$ and acrylonitrile was obtained from Sigma-Aldrich (St. Louis, MO, USA) and FUJIFILM Wako Pure Chemical Industries (Tokyo, Japan), respectively. Polyacrylamide (MW. 5000-6000 kDa), as a chemical for the pore formation, and 2-hydroxy-2-methylpropiophenone (HMP), as a photoinitiator, were purchased from FUJIFILM Wako Pure Chemical Corporation (Osaka, Japan) and Tokyo Chemical Industry Co. (Tokyo, Japan), respectively. The UV lamp used for the polymerization was Model UVGL-25 (Funakoshi Co., Ltd., Tokyo, Japan). Silica particles used had 1 and $10 \mu \mathrm{m}$ diameter and were purchased from micromod (Partikeltechnologie GmbH, Rostok, Germany). Nannochloropsis sp. (Marine fresh, 0606) was obtained 
from Higashimaru Co., Ltd. (Kagoshima, Japan). An optical image of Nannochloropsis sp. is shown in Appendix A (Figure A1).

The cross flow for the permeation through the membrane was lab-made equipment. The filter holder (diameter: $5.9 \mathrm{~cm}$ ), $\mathrm{O}$ ring, pressure gauge, and peristat pump were from Merck KGaA(SX0004700), MonotaRO Co., Ltd. (Amagasaki, Japan) (ARP568-30A, diameter $41 \mathrm{~mm}$, nitrile rubber, wire diameter $1.78 \mathrm{~mm}$ ), Nagano Keiki Co., Ltd. (Higashimagome, Japan), and Tokyo Rikakikai Co., Ltd. (Tokyo, Japan) (ROLLER PUMP, RP-2000), respectively. Other chemicals were of analytical grade or higher. UV-Vis for the determination of the concentration of colloidal particles was JASCO Corporation (V-630BIO, Tokyo, Japan).

\subsection{Preparation of Elastic Membrane}

PEGDA, acrylonitrile, and HMP were measured at the mass shown in Table 1 and mixed with polyacrylamide (PAA) solution $(10 \mathrm{~g} / \mathrm{L})$. After dissolution, nitrogen gas was purged to the solution to remove oxygen for $1 \mathrm{~min}$. The solution was added to a petri dish and sealed at the nitrogen atmosphere. A UV lamp at the wavelength of $365 \mathrm{~nm}$ was irradiated to the solution for polymerization for one hour at room temperature in a dark room. The heat flux was set at $0.72 \times 10^{-3} \mathrm{~W} / \mathrm{cm}^{2}$. After the polymerization, the obtained membrane was washed with water repeatedly. The membrane without added PAA was also prepared with the same procedure for comparison. The porosity of the membrane was determined by the weight change before and after the membrane was immersed in water. To determine the elastic modulus of the membrane, the dynamic ultra micro hardness tester (DUH-211S, Shimadzu, Kyoto, Japan) was performed three times.

Table 1. Preparation of elastic membrane.

\begin{tabular}{ccc}
\hline \multirow{2}{*}{ Chemicals } & \multicolumn{2}{c}{ Amount of Chemicals } \\
\cline { 2 - 3 } & Mass [g] & Mole [mol] \\
\hline Acrylonitrile & 0.90 & 0.017 \\
Poly(ethylene glycol) diacrylate $(\mathrm{n}=10)$ & 2.0 & 0.0034 \\
Polyacrylamide & 0.080 & $1.4 \times 10^{-8}$ \\
Distilled water & 7.9 & 0.44 \\
2-Hydroxy-2-methylpropiophenenone & 0.050 & 0.00030 \\
\hline
\end{tabular}

\subsection{Permeation of Water and Colloidal Particle Suspension through Elastic Membrane}

The permeation apparatus is illustrated in Figure 2. The cross flow for the permeation through the membrane was lab-made equipment, as shown in Figure A2 in Appendix A. The prepared flat-sheet membrane was cut at the diameter of $47 \mathrm{~mm}$. The membrane was set at the filter folder and water was flowed at the prescribed pressure to calculate the water flux, $\mathrm{m}^{3} / \mathrm{m}^{2} \cdot \mathrm{min}$. The pressure was controlled with the lever of the peristat pump to set a constant pressure of $0.010 \mathrm{MPa}$. The effluent volume was measured for a prescribed time, and the mass was changed to the effluent volume by a density of $1000 \mathrm{~kg} / \mathrm{m}^{3}$. After the water permeation, the pressure was again applied for the determination of water flux for repeated measurements. 


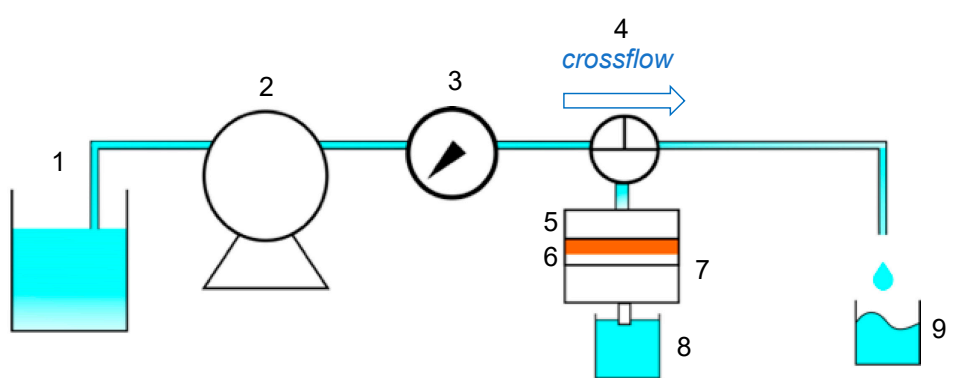

Figure 2. Cross flow apparatus of elastic membrane. 1: Feed solution, 2: pump, 3: pressure gauge, 4: three-way cock, 5: filter holder, 6: elastic membrane, 7: O ring, 8: elution, 9: recovery solution by cross flow.

Suspensions of silica particles ( 1 and $10 \mu \mathrm{m}, 0.1 \mathrm{~g} / \mathrm{L})$ and Nannochloropsis sp. $(2 \mu \mathrm{m}$, $0.1 \mathrm{~g} / \mathrm{L}$ ) were individually permeated through the membrane at $0.01 \mathrm{MPa}$. The concentration of colloidal particles was determined by the wavelength of $600 \mathrm{~nm}$ of UV-Vis (JASCO Corporation, V-630BIO, Japan).

\subsection{Recovery of Filtered Particles by Elastic Membrane}

Suspensions of silica particles $(10 \mu \mathrm{m}, 0.1 \mathrm{~g} / \mathrm{L})$ and Nannochloropsis sp. $(2 \mu \mathrm{m}, 0.1 \mathrm{~g} / \mathrm{L})$ were firstly permeated to the elastic membrane at $0.01 \mathrm{MPa}$ for $30 \mathrm{~min}$ by the apparatus of Figure 2. After filtration, the applied pressure was released to make the filtered residues rise up. Subsequently, cross flow at $2760 \mathrm{~mL} / \mathrm{h}$ above the membrane surface was performed for $30 \mathrm{~s}$. The concentration in each effluent and recovered beaker, at 8 and 9 in Figure 2, respectively, was determined by UV-Vis. The percentage of filtered particle was defined as follows.

Percentage of filtered particle [\%] = $100(1-($ amount of filtered particle $)) /($ initial amount of particle).

\section{Results and Discussion}

\subsection{Preparation of Elastic Membrane}

Poly(ethylene glycol) diacrylate and acrylonitrile were polymerized with the photopolymerization by adding PAA. Here, the polymerization of poly(ethylene glycol diacrylate) and acrylonitrile was already confirmed by infrared in the previous published papers [15]. The SEM image of the obtained elastic flat-sheet membrane was shown in Figure 3. The obtained membrane had the diameter and thickness of $6.5 \mathrm{~cm}$ and $1.8 \mathrm{~mm}$, respectively. The outer edge of the membrane had the thickness of $2.0 \mathrm{~mm}$ because the monomer transferred to the wall of the petri dish via flow convection generated by surface tension. The porosity determined was $73 \%$. The surface of the membrane was observed, as shown in Figure 3. The three different domains of the membrane were observed. Acrylonitrile, PAA, and PEGDA have the role of membrane matrix, pore formation, and elasticity of the membrane, respectively. Ethylene glycol in PEGDA especially has the ability of extension and shrinkage because of the spring structure of ethylene glycol. The pore of the membrane was $1-10 \mu \mathrm{m}$, applicable for the filtration of appropriated particles. 

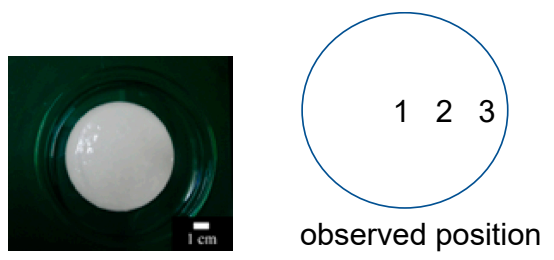

1

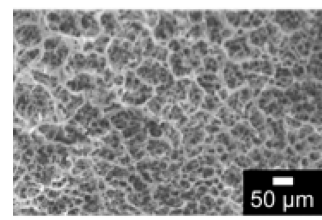

2

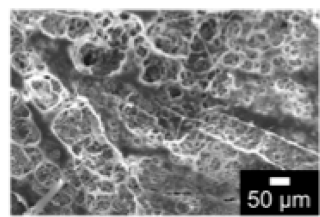

3

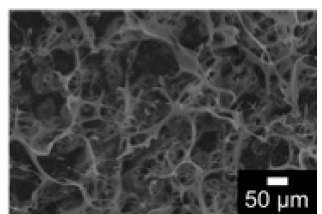

Figure 3. SEM images of the elastic membrane.

The elastic modulus of the obtained membrane with PAA was $25.2 \mathrm{~N} / \mathrm{mm}^{2}$. Drira and Yadavalli determined the mechanical strength of poly(ethylene glycol) hydrogel by atomic force microscopy, demonstrating that the gel had the elastic modulus of $1.3 \mathrm{~N} / \mathrm{mm}^{2}$ [16]. As the elasticity was dependent on the polymerization conditions as well as used monomers, the obtained membrane had higher elasticity due to the presence of PAA and macropore formation.

\subsection{Filtration of Each Particle through Elastic Membrane}

Flux changes at different pressures through the elastic flat-sheet membrane prepared with and without adding PAA is shown in Figure 4. The experiments were performed three times to check the reproducibility. The membrane without PAA showed the linear increment of flux with increasing applied pressure, whereas the membrane with PAA had the non-linear increase, demonstrating that the flat-sheet membrane would exhibit the deformation of the membrane because of the pressure. Figure 4 shows that the membrane with PAA represented the higher flux, demonstrating that the macromolecules such as PAA have the higher exclusion volume to form the large pore in the membrane. After the washing, a part of PAA would be leaked from the membrane. The repeated permeation of water to the membrane was performed, as Figure 4 shows, demonstrating that the flux obtained has reproducible data. Thus, the membrane had a reversible deformation against the applied hydrodynamic pressure.
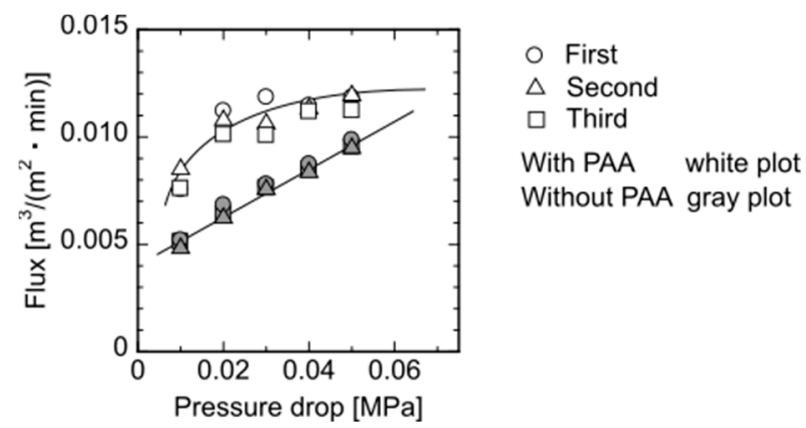

Figure 4. Steady-state flux of the membrane as a function of applied pressure. Each pressure was performed three times for reproducibility.

Silica suspension $(1$ and $10 \mu \mathrm{m})$ and Nannochloropsis sp. $(2 \mu \mathrm{m})$ suspension were individually permeated through the elastic membrane with PAA to determine the permeation flux and concentration change in the effluent, as shown in Figure 5. In the case of silica suspension, the flux and concentration in the effluent decreased, whereas in the case of Nannochloropsis sp., they increased and levelled off. In the case of $1 \mu \mathrm{m}$ of silica, as shown in Figure 5, the flux decreased to show the lower concentration in the effluent than the 
initial concentration. This is due to the filtration of silica and the transfer of silica in the membrane by convection to the effluent. Twenty percent of silica $(1 \mu \mathrm{m})$ was filtered in the membrane, resulting in a reduction in the permeation flux. In the case of $10 \mu \mathrm{m}$ of silica, the flux decreased and the concentration in the effluent was decreased because of the deposition of silica on the membrane.

The surface of the membrane after the filtration was observed by SEM, as shown in Figure 6. The image of $10 \mu \mathrm{m}$ of silica showed the filtered particles on the membrane surface. An amount of $1 \mu \mathrm{m}$ of silica would be filtered on the membrane, and a part of the silica filtered in the membrane as a depth filtration. Figure $6 \mathrm{c}$ shows that some of the filtered Nannochloropsis sp. was observed on the membrane.

\section{Nannochloropsis sp.}

- $10 \mu \mathrm{m}$ silica

- $1 \mu \mathrm{m}$ silica
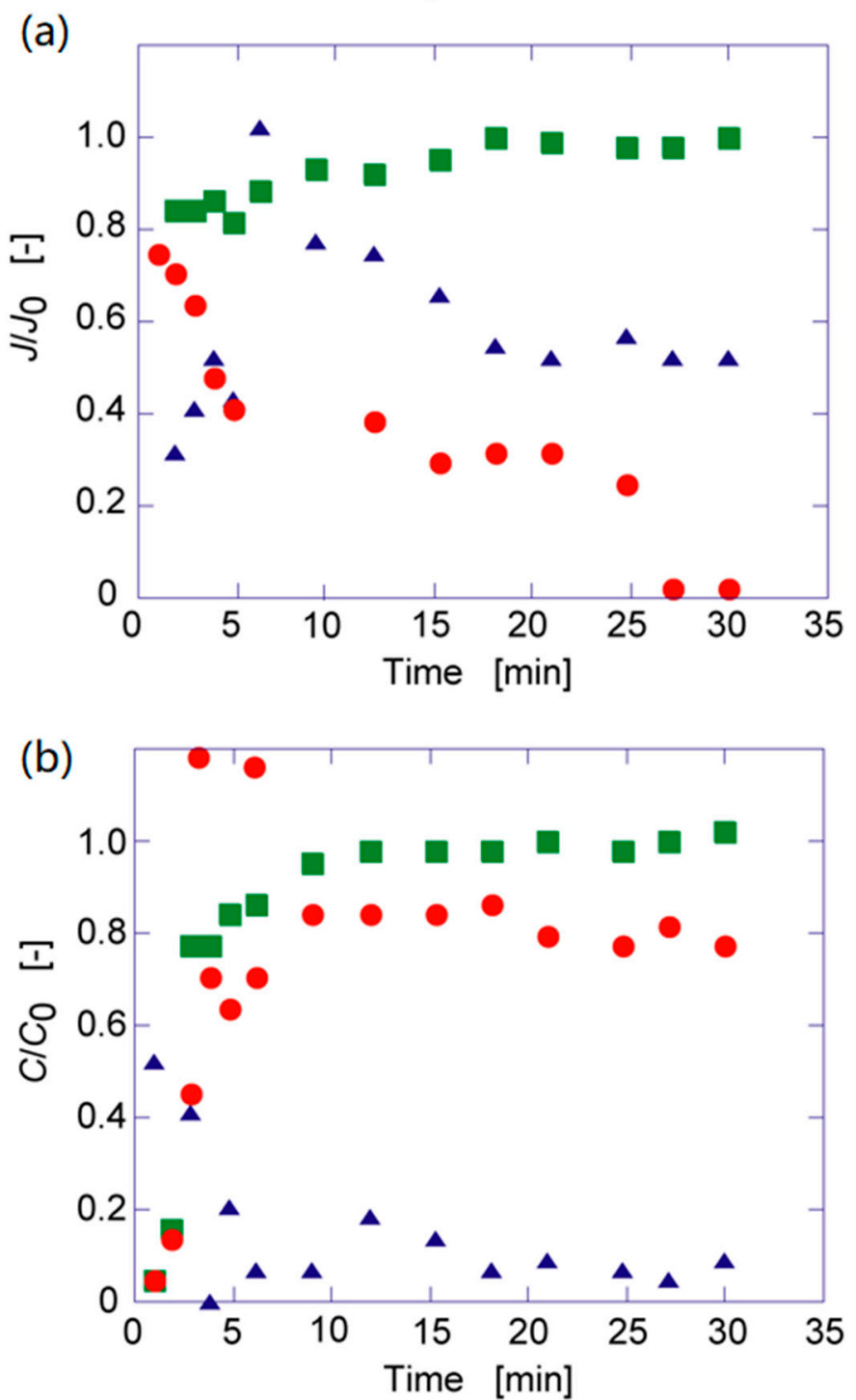

Figure 5. Time course curves of (a) flux ratio and (b) concentration ratio of each particle to the prepared elastic membrane. 
(a) $1 \mu \mathrm{m}$ silica

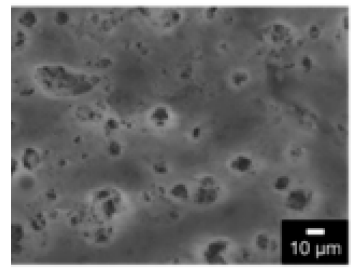

(b) $10 \mu \mathrm{m}$ silica

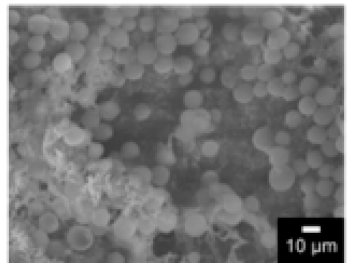

(c) Nannochloropsis sp.

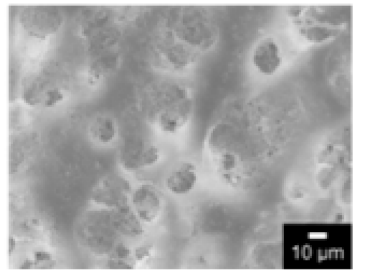

Figure 6. SEM images of the surface of the membrane after the filtration of each particle. (a) $1 \mu \mathrm{m}$ silica; (b) $10 \mu \mathrm{m}$ silica; (c) Nannochloropsis sp.

\subsection{Recovery of Filtered Particles by Restoring the Elastic Membrane and Cross Flow}

The filtered silica $(10 \mu \mathrm{m})$ and Nannochloropsis sp. $(2 \mu \mathrm{m})$ by the elastic membrane was recovered by the elasticity and cross flow, as shown in the scheme of Figure 1. Elution percentage, percentage remaining in the membrane and recovered percentage by cross flow are summarized in Table 2. The filtration percentage was higher for silica $(10 \mu \mathrm{m})$. The recovery percentage of silica $(10 \mu \mathrm{m})$ by cross flow was $71 \%$. Silica was filtered on the membrane due to its larger size, and a large amount of silica filtered was raised up by the elasticity of the membrane, followed by the recovery by the cross flow. In the case of Nannochloropsis sp., the recovery percentage by cross flow was $0.93 \%$. Nannochloropsis sp. at the smaller size passed through the membrane, resulting in the lower recovery percentage. During the filtration, the particles filtered were captured via adhesion, showing that the interaction of the target and the membrane should be considered for high recovery percentage by raising the filtered particles up by the elasticity of the membrane and cross flow.

Table 2. Percentage of filtered particles using elasticity of the membrane and crossflow.

\begin{tabular}{cccc}
\hline & \multicolumn{3}{c}{ Percentage of Particle [\%] } \\
\hline Filtered particles & elution & remaining in the membrane & recovered by crossflow \\
10 mm silica & 14 & 15 & 71 \\
$2 \mathrm{~mm}$ Nannochloropsis sp. & 93 & 6.1 & 0.93 \\
\hline
\end{tabular}

\section{Conclusions}

The recovery scheme of filtered particles by the elasticity of the flat-sheet membrane has been proposed. Acrylonitrile and poly(ethylene glycol) diacrylate were photopolymerized by adding polyacrylamide. Ethylene glycol had a role of spring for elasticity and polyacrylamide formed a pore of the flat-sheet membrane. The observation by SEM demonstrated that the membrane had a pore of $10 \mu \mathrm{m}$. For the recovery of filtered particles, the water was permeated from the bottom of the membrane to raise the filtered particles up, and cross flow above the membrane was applied for the recovery of the filtered particles. Silica at $10 \mu \mathrm{m}$ had a high filtration percentage and could be recovered by the elasticity of the membrane and cross flow. At present, the particles filtered by the membrane are recovered by a spoon by hand. The proposed method has the potential to recover the filtered particles by using the porous membrane.

Author Contributions: Conceptualization, H.K.; methodology, M.M.; validation, M.M.; formal analysis, M.M.; investigation, M.M.; writing—original draft preparation, H.K.; writing-review and editing, H.K.; visualization, H.K.; supervision, S.M., K.O.; project administration, H.K.; funding acquisition, H.K. All authors have read and agreed to the published version of the manuscript.

Funding: This research was partially funded by Ceramic Research Center of Saga University.

Institutional Review Board Statement: Not applicable.

Informed Consent Statement: Not applicable. 
Data Availability Statement: Data is contained within the article.

Acknowledgments: We are thankful for the financial support from Ceramic Research Center of Saga University, Japan. The analysis of materials was supported by Analytical Research Center for Experimental Sciences, Saga University.

Conflicts of Interest: The authors declare no conflict of interest.

\section{Appendix A}

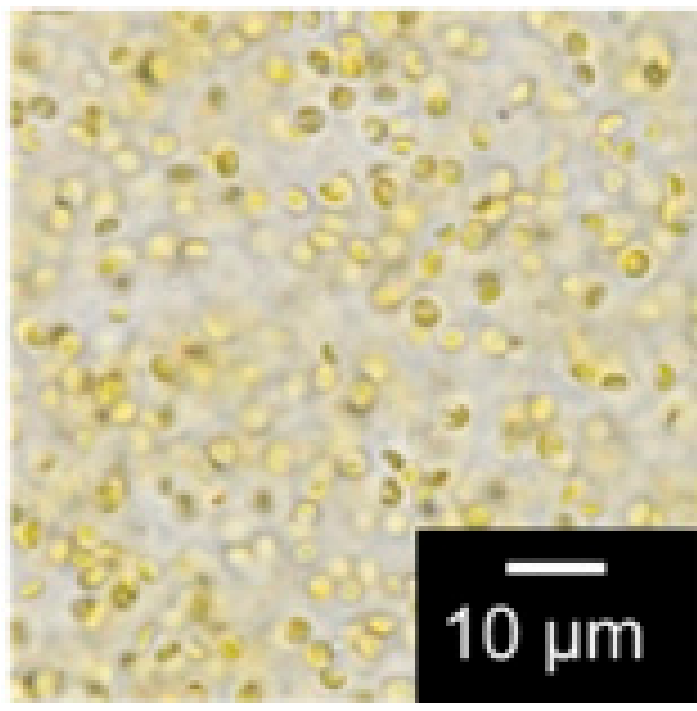

Figure A1. Optical image of Nannochloropsis sp.
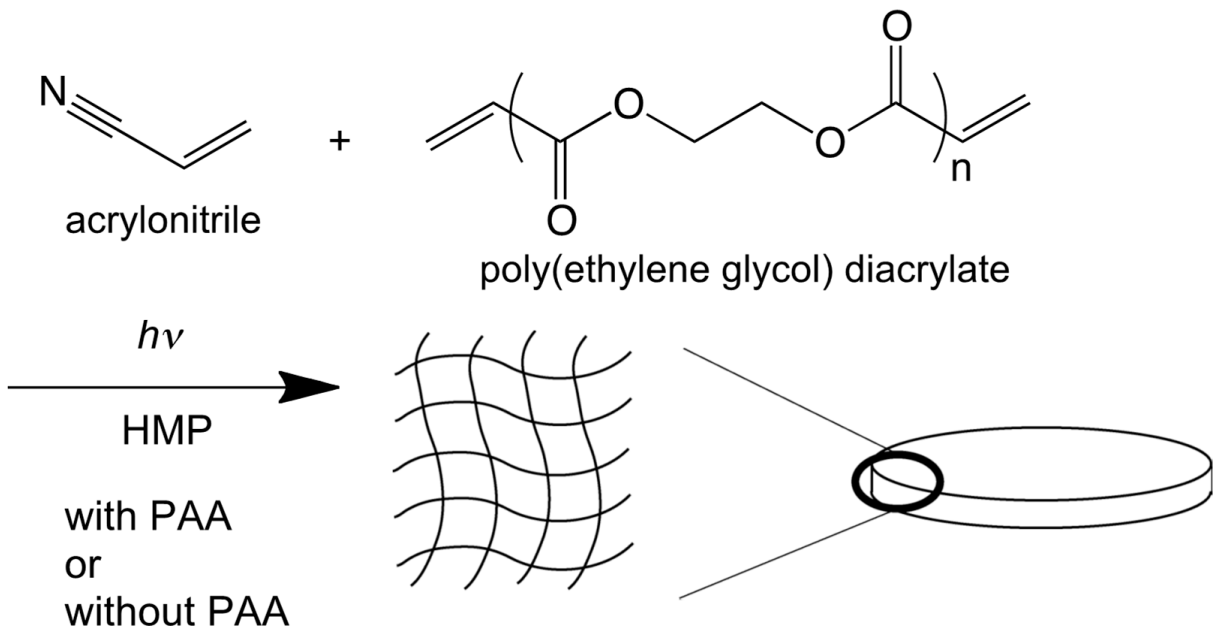

Figure A2. Preparation scheme of elastic membrane. 


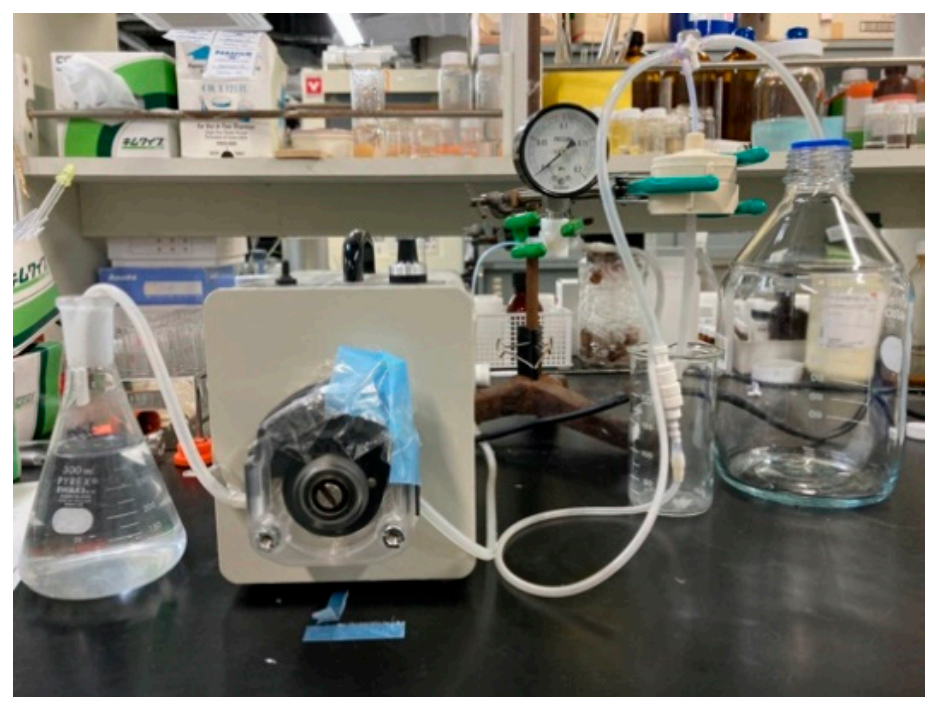

Figure A3. Picture of permeation apparatus.

\section{References}

1. Schiffer, S.; Kulozik, U. Effect of temperature-dependent bacterial growth during milk protein fractionation by means of $0.1 \mu \mathrm{m}$ microfiltration on the length of possibly production cycle times. Membranes 2020, 10, 326. [CrossRef] [PubMed]

2. Jamal, S.; Chang, S.; Zhou, H. Filtration behavior and fouling mechanisms of polysaccharides. Membranes 2014, 4, 319-332. [CrossRef] [PubMed]

3. Takaoka, Y.; Morisada, S.; Ohto, K.; Kawakita, H. Filtration of colloidal particles using compacted-gel media packed in a column. J. Chem. Eng. Jpn. 2017, 50, 815-820. [CrossRef]

4. Takaoka, Y.; Esaki, S.; Sakaguchi, K.; Fujisawa, T.; Unno, M.; Morisada, S.; Ohto, K.; Kawakita, H. Size-dependent separation of graphene oxide by deformation of packed-gel in a chromatographic column. Sep. Sci. Technol. 2019, 55. [CrossRef]

5. Miyoshi, M.; Takayanagi, K.; Morisada, S.; Ohto, K.; Kawakita, H.; Morita, S. Size separation of silica particles using a magnetitecontaining gel-packed column. Processes 2019, 7, 201. [CrossRef]

6. Takaoka, Y.; Miyoshi, M.; Sakaguchi, K.; Morisada, S.; Ohto, K.; Kawakita, H. Recovery of filtered graphene oxide residue using elastic gel packed in a column by cross flow. Processes 2018, 6, 43. [CrossRef]

7. Shen, C.; Bian, L.; Zhang, P.; An, B.; Gui, Z.; Wang, H.; Li, J. Microstructure evolution of bonded water layer and morphology of grafting membrane with different polyethylene glycol length and their influence on permeability and anti-fouling capacity. $J$. Membr. Sci. 2020, 601, 117949. [CrossRef]

8. Miller, D.J.; Araujo, P.A.; Correia, P.B.; Ramsey, M.M.; Kruithof, J.C.; Loosdrecht, M.C.M.; Freeman, B.D.; Paul, D.R.; Whiteley, M.; Vrouwenvelder, J.S. Short-term adhesion and long-term biofouling testing of polydopamine and poly(ethylene glycol) surface modifications of membranes and feed spacers for biofouling control. Water Res. 2012, 46, 3737-3753. [CrossRef]

9. Ju, H.; McCloskey, B.D.; Sagle, A.C.; Kusuma, V.A.; Freeman, B.D. Preparation and characterization of crosslinked poly(ethylene glycol) diacrylate hydrogels as fouling-resistant membrane coating materials. J. Membr. Sci. 2009, 330, 180-188. [CrossRef]

10. Duprat, C.; Berthet, H.; Wexler, J.S.; du Roure, O.; Anke, L. Microfluidic in situ mechanical testing of photopolymerized gels. Lab Chip 2015, 15, 244-252. [CrossRef]

11. Persson, K.M.; Gekas, V.; Trägårdh, G. Study of membrane compaction and its influence on ultrafiltration water permeability. J. Membr. Sci. 1995, 100, 155-162. [CrossRef]

12. Islam, M.A.; Stoicheva, R.N.; Dimov, A. An investigation on the deformational properties of porous poly(vinyl chloride) and co-poly(butadiene-acrylonitrile) blend membranes. J. Membr. Sci. 1996, 118, 9-15. [CrossRef]

13. Cappello, J.; d'Herbemont, V.; Lindner, A.; du Roure, O. Microfluidic in-situ measurement of Poisson's ratio of hydrogels. Micromachines 2020, 11, 318. [CrossRef] [PubMed]

14. Zhong, C.; Wu, J.; Reinhart-King, C.A.; Chu, C.C. Synthesis, characterization and cytotoxicity of photo-crosslinked maleic chitosan-polyethylene glycol diacrylate hybrid hy-drogels. Acta Biomater. 2010, 6, 3908-3918. [CrossRef] [PubMed]

15. Kang, G.; Cao, Y.; Zhao, H.; Yuan, Q. Preparation and characterization of crosslinked poly(ethylene glycol) diacrylate membranes with excellent antifouling and solvent-resistance properties. J. Membr. Sci. 2008, 318, 227-1232. [CrossRef]

16. Drira, Z.; Yadavalli, V.K. Nanomechanical measurements of polyethyeleglycol hydrogels using atomic force microscopy. J. Mechanic. Behav. Biomed. Mater. 2013, 18, 20-28. [CrossRef] 